\title{
LIPIDS AND DUPUYTREN'S DISEASE
}

\author{
P. L. SANDERSON, M. A. MORRIS, J. K. STANLEY, N. R. M. FAHMY
}

From Stockport Infirmary and Wrightington Hospital, Wigan

\begin{abstract}
We studied prospectively the relationship between serum lipids and Dupuytren's disease of the hand in 85 patients, 65 men and 20 women. The Dupuytren patients had significantly higher fasting serum cholesterol and triglyceride levels than did the controls $(p<0.001)$. The raised levels of serum lipids appeared to be associated with the pathogenesis of Dupuytren's disease, and this may help to explain the high incidence of Dupuytren's disease in alcoholic, diabetic and epileptic patients, since these conditions are also associated with raised serum lipid levels.
\end{abstract}

The earliest reference to Dupuytren's disease is attributed to Plater in 1614 (Elliot 1990). Dupuytren (1833) first recognised that the pathology lay in the palmar fascia, and the disease now bears his name. Understanding of this peculiar disease has progressed slowly over the last 150 years, despite the fact that, in England, it affects over $4 \%$ of the male population (Early 1962).

There is a familial tendency, with an incidence of up to $70 \%$ in the relatives of patients (Ling 1963). The conditions associated with Dupuytren's disease include alcoholism (Pojer, Radivojevic and Williams 1972), diabetes (Noble, Heathcote and Cohen 1984) and epilepsy (Early 1962; Critchley et al 1976).

The relationship of Dupuytren's disease to epilepsy is unclear; some authors have suggested that there is a genetic link (Lund 1941; Early 1962; James 1974), while others (Skoog 1948; Critchley et al 1976) have proposed that the high incidence is related to the drugs, especially phenobarbitone, used to treat epilepsy. Both alcoholism and diabetes are associated with raised serum triglyceride

P. L. Sanderson, FRCS Ed, Registrar in Orthopaedics

J. K. Stanley, MCh Orth, FRCS, FRCS Ed, Consultant Hand Surgeon Department of Orthopaedics, Wrightington Hospital, Appley Bridge, near Wigan, Lancashire WN6 9EP, England

M. A. Morris, FRCS, Consultant Orthopaedic Surgeon

N. R. M. Fahmy, FRCS Ed, Consultant Orthopaedic Surgeon

Department of Orthopaedics, Stockport Infirmary, Wellington Road South, Stockport, Cheshire SK 1 3UJ, England.

Correspondence should be sent to Mr P. L. Sanderson at 'Conister', 161 Market Street, Whitworth, near Rochdale, Lancashire OL12 8RU, England.

(C) 1992 British Editorial Society of Bone and Joint Surgery

$0301-620 \mathrm{X} / 92 / 6474 \$ 2.00$

J Bone Joint Surg [Br] 1992; 74-B:923-7. levels (Havel 1979) and phenobarbitone is known to increase cholesterol metabolism (Harvey 1980).

Our aim was to identify any relationship between serum lipid levels and Dupuytren's disease.

\section{PATIENTS AND METHODS}

The diagnosis of Dupuytren's disease was made by one of the authors (PLS) on the basis of one or more palmar nodules, a digital nodule, a pretendinous band or a digital contracture.

The severity of the disease was staged by the method of Early (1962). In this system, points are allocated for each contracted digit according to the sum of the degrees of flexion deformity in all its joints.

Palmar nodules only score 0 points, a total digital deformity of $60^{\circ}$ or less scores 1 point, of $61^{\circ}$ to $120^{\circ} 2$ points, and over $120^{\circ} 3$ points. The addition of the points for each digit then gives the staging of the disease for the hand. A score of 1 is stage I, a score of 2 or 3 is stage II, scores of 4 to 6 are stage III, and a score of over 6 represents stage IV.

Patients with Dupuytren's disease who attend for a surgical opinion are a selected group. To assess a broader cross-section of the population, we examined all patients who attended an orthopaedic outpatient clinic for any condition over a period of 12 months. All those found to have Dupuytren's disease were asked to attend a special review clinic, but we excluded patients who had had previous operations for Dupuytren's disease.

The patients were instructed to have nothing to eat or drink for ten hours before attending so that their serum lipid results would relate to standard fasting levels. The severity of the contractures was measured with a goniometer, and blood was taken for serum triglyceride and cholesterol concentrations. A record was made of 
any family history of Dupuytren's disease, and whether the patient suffered from diabetes, epilepsy or alcoholism, which was defined as an alcohol intake of $40 \mathrm{~g}$ or more daily (Bradlow and Mowat 1986).

The control series was matched for decade of age and for sex from those admitted for elective orthopaedic operations during the same period. Similar measurements of fasting serum triglycerides and cholesterol were made. We have no record of the incidence of diabetes, epilepsy or excess alcohol intake in the control series. The mean age of the control series was 1.5 years older than that of the patients.

\section{RESULTS}

We assessed a total of 85 consecutive patients with Dupuytren's disease of the hand, 50 from Stockport, and 35 from Wrightington. There were 65 men with a mean age of 63 years ( 29 to 84 ) and 20 women with a mean age of 69 years ( 56 to 89). Eight patients were unaware that they had the condition and $22(26 \%)$ were aware of a family history of Dupuytren's disease. The distribution of the stages of contracture is shown in Figure 1. A positive family history was more common in patients with stage II to IV contractures (13 of $33: 39 \%$ ) than in those with stage 0 or I ( 9 of 52: 17\%). Eight patients ( $9 \%$ ) were diabetic and four (4.7\%) admitted a high alcohol intake. No patient in the study was suffering from epilepsy.

The results of the lipid measurements are shown in Figure 2a. The mean \pm SD serum cholesterol concentration in patients with Dupuytren's disease was $6.69 \pm 1.3$ $\mathrm{mmol} / \mathrm{l}$ compared with $5.85 \pm 0.98 \mathrm{mmol} / \mathrm{l}$ in the control patients ( $\mathrm{p}<0.001$, Student's $t$-test). The mean serum triglyceride concentration in Dupuytren patients was $1.67 \pm 0.8 \mathrm{mmol} / 1$ and in the controls, $1.23 \pm 0.42$ $\mathrm{mmol} / \mathrm{l}(\mathrm{p}<0.001)$. These results are related to the stage of disease in Figure $2 \mathrm{~b}$; there was no significant correlation between severity of the contracture and serum lipid levels. The exclusion of the values for the 12 patients with diabetes or high alcohol intake did not alter the significance levels of the differences from the control series.

\section{DISCUSSION}

The association of Dupuytren's disease with certain other conditions suggests that there may be some common pathway of aetiology or pathogenesis. Our results show that patients with Dupuytren's disease have significantly higher mean serum triglyceride and cholesterol levels

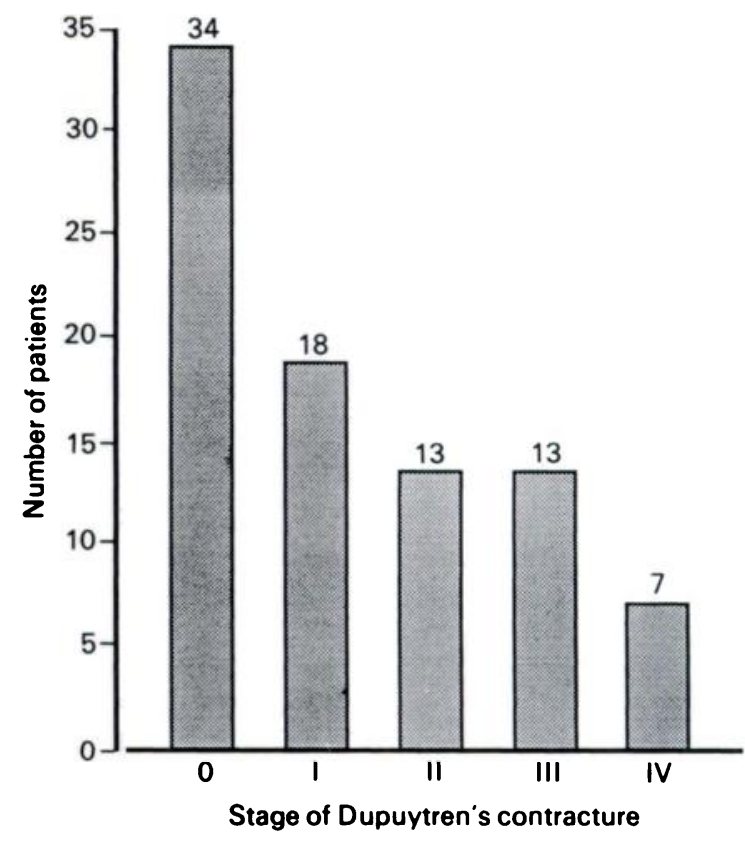

Fig. 1

Stage of Dupuytren's contracture in the 85 patients studied (see text).
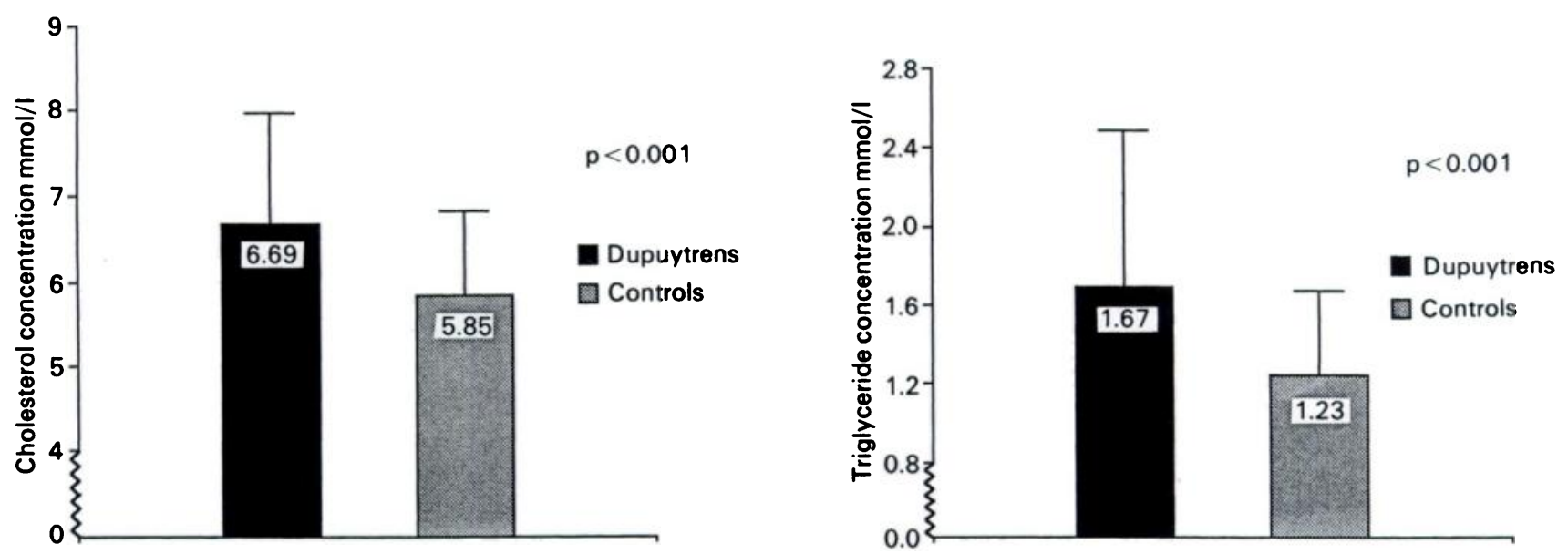

Fig. 2a

Mean serum cholesterol and triglyceride concentrations in Dupuytren and control patients. 


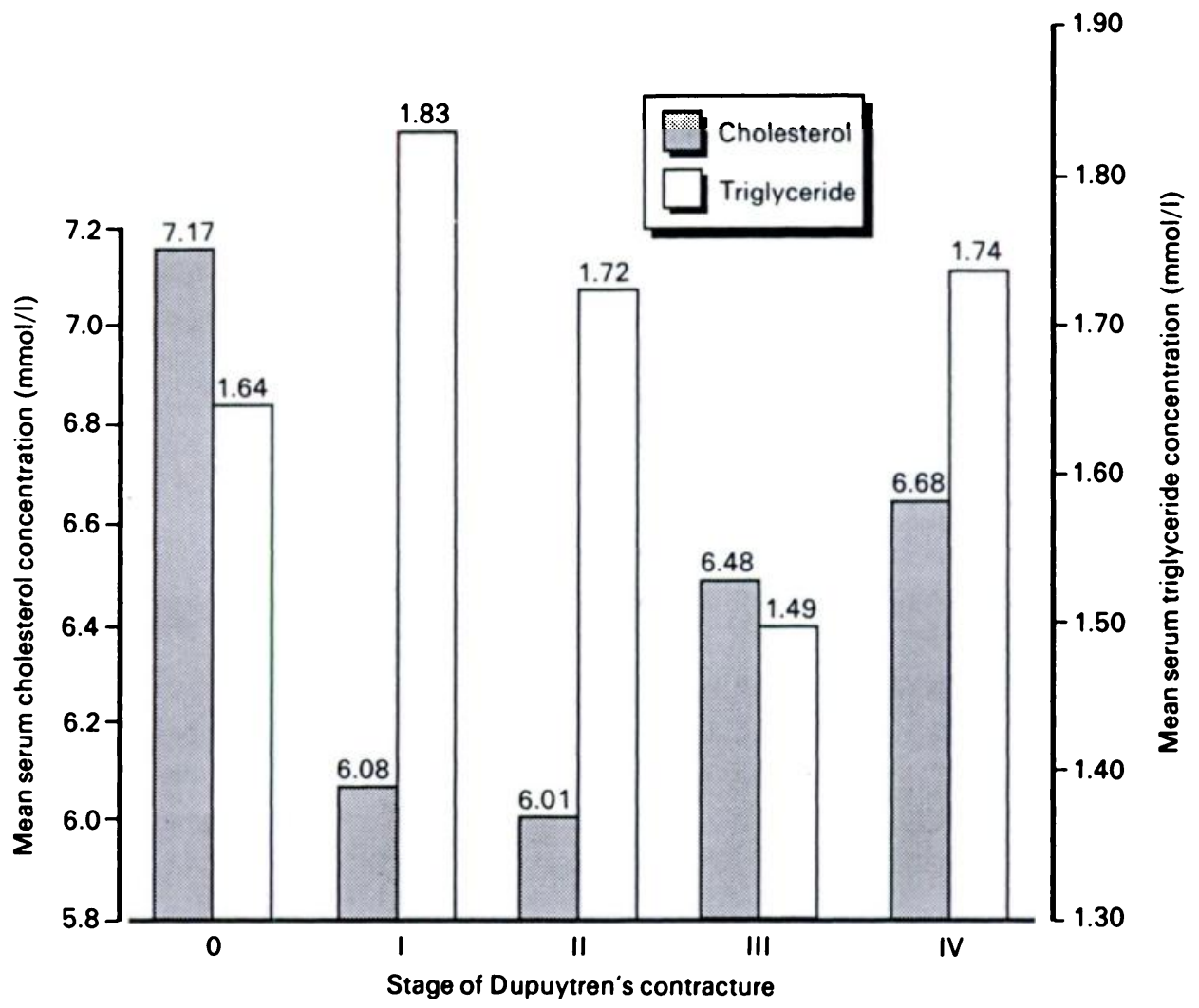

Fig. 2b

Mean serum cholesterol and triglyceride concentrations related to the stage of the Dupuytren's contracture.

than a control series matched for age by decade and for sex. It seems possible that these raised lipid levels may be related to the pathogenesis, since it is known that both alcoholism and diabetes result in raised serum triglyceride concentrations (Havel 1979) and that the phenobarbitone given for epilepsy influences cholesterol metabolism (Harvey 1980). Alcoholism, diabetes and epilepsy are all associated with an increase in the incidence of Dupuytren's disease (Pojer et al 1972; Critchley et al 1976; Noble et al 1984).

The serum triglyceride concentration increases with age, both in males and females, but this occurs much earlier in men than in women in whom it tends to rise around the time of the menopause (Fig. 3). Dupuytren's disease also tends to develop at an earlier age in men than in women, a fact which has not been adequately explained. In our series the youngest man was 29 years of age whereas the youngest woman was 56 years; Dupuytren's disease in women is reported to be rare before the age of 50 years (Hueston 1960; Early 1962). The increase in incidence of the condition with age may be associated with the increasing level of serum triglycerides, and this may possibly be why the disease occurs later in women (Fig. 3).

Flint (1990) has observed that Dupuytren's disease starts on either side of the distal palmar crease, but rarely on it, where there is no palmar fat. He also believes that the disease probably begins in the superficial longitudinal fibres of the palmar fascia, where they are surrounded by loculated fat. The use of fat-free, full-thickness skin grafts has been shown to reduce the recurrence of Dupuytren's disease after surgery (Tonkin, Burke and Varian 1984; Hueston 1985), which tends to confirm the role of the palmar dermis and is possibly related to its fat content.

Rabinowitz et al (1983) studied the fat in the palmar dermis of patients suffering from Dupuytren's disease comparing its composition with that in the palmar dermis of control subjects without disease, and found raised levels of cholesterol and fatty acids. They attributed this difference to the effects of hypoxia, but it is possible that it is related to the elevated levels of serum cholesterol and triglycerides which we have found to occur in Dupuytren's disease.

Cholesterol and triglycerides are transported in the form of lipoproteins, and these have been shown to bind to type I collagen (Hoover, McCormick and Kalant 1988), which is the predominant type of collagen in palmar fascia. This binding is greatly increased when free radicals are present, and these have been shown to be increased in patients with Dupuytren's disease (Murrell, Francis and Bromley 1987). Low-density lipoproteins and cholesterol are cytotoxic to fibroblasts in high concentrations; this cytotoxicity is due to the products of lipid peroxidation (Kandutsch, Heiniger and Chen 1977; Evensen, Galdal and Nilsen 1983), which occurs via oxygen-derived free radicals, abundant in 

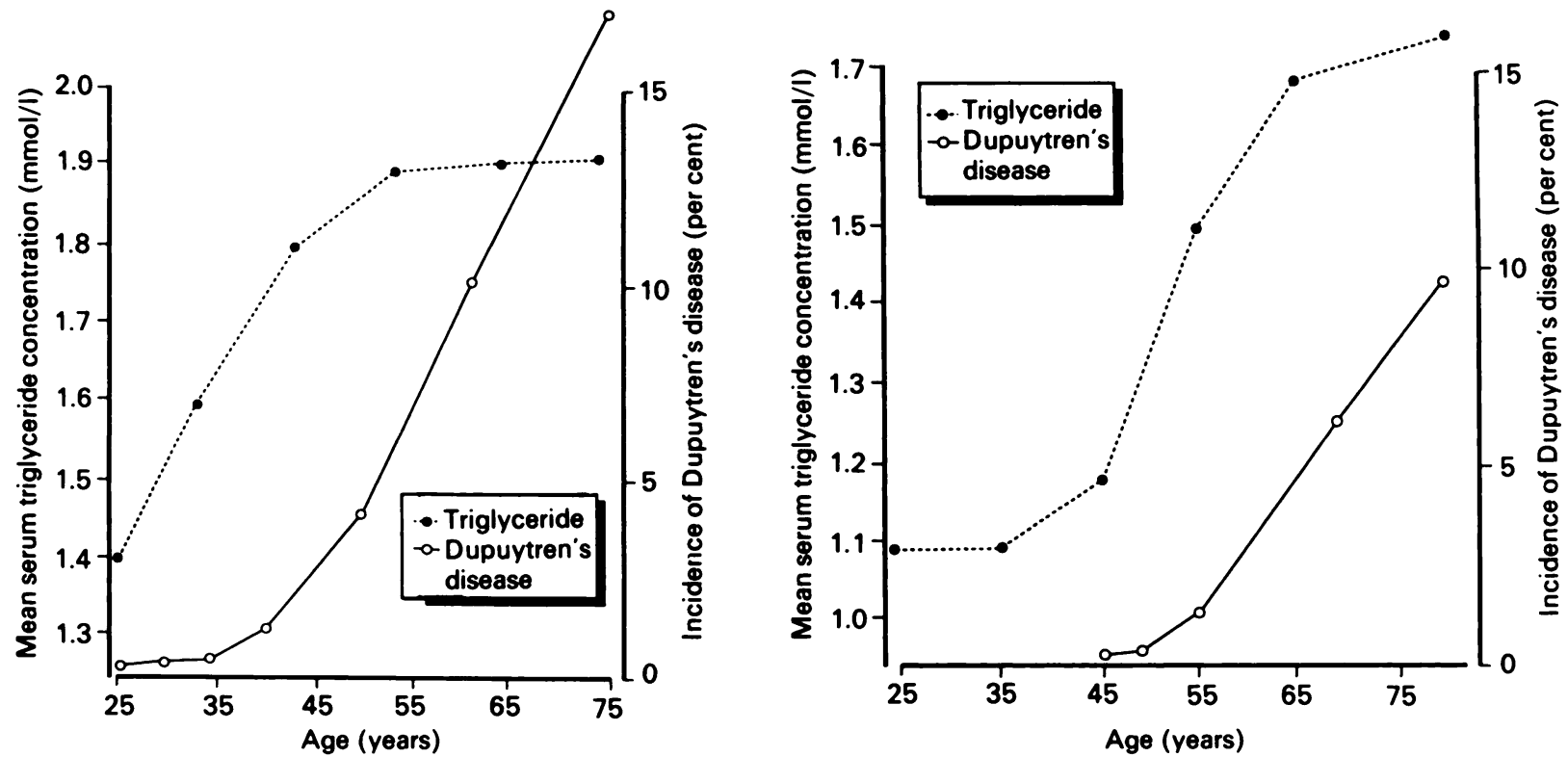

Fig. 3

Graphs relating the age-related rise in serum triglycerides to the increase in incidence of Dupuytren's disease. In men (left) there is an earlier rise in both variables than in women (right). The data are from Early (1962) and Ball and Mann (1988).

Dupuytren's disease. It may be that the toxicity of the lipids induces a reparative response by surrounding fibroblasts. This response may account for the increase in type III collagen seen in Dupuytren's disease (BrickleyParsons et al 1981), and may also be the cause of the contractures of the palmar fascia.

We found no significant correlation between serum lipid levels and the severity of the contracture. This suggests that the severity of the disease is under influences other than the lipid levels, and it is possible that abnormal lipids are responsible only for the initiation of the disease process. The importance of genetic factors is evident from the finding that a positive family history is significantly related to the aggression of the disease (McFarlane 1990).

Conclusions. We have found significantly higher levels of serum triglycerides and cholesterol in patients with Dupuytren's disease and have discussed their relationship to the pathogenesis of the disease in genetically predisposed patients. There is need for further work on the influence of lipids on the palmar fascia of patients suffering from Dupuytren's disease.

No benefits in any form have been received or will be received from a commercial party related directly or indirectly to the subject of this article.

\section{REFERENCES}

Ball M, Mann J. Lipids and heart disease : a practical approach. First ed. Oxford University Press, 1988; 8-19.

Bradlow A, Mowat AG. Dupuytren's contracture and alcohol. Ann Rheum Dis 1986; $45: 304-7$.

Brickley-Parsons D, Glimcher MJ, Smith RJ, Albin R, Adams JP. Biochemical changes in the collagen of the palmar fascia in patients with Dupuytren's disease. J Bone Joint Surg [Am] 1981; 63-A :787-97.

Critchley EM, Vakil SD, Hayward HW, Owen VMH. Dupuytren's disease in epilepsy: result of prolonged administration of anticonvulsants. J Neurol Neurosurg Psychiatry 1976; 39:498-503.

Dupuytren G. Permanent retraction of the fingers, produced by an affection of the palmer fascia. Lancet 1833-4; ii :222-5.

Early PF. Population studies in Dupuytren's contracture. J Bone Joint Surg $[\mathrm{Br}] 1962 ; 44-\mathrm{B}: 602-13$.
Elliot D. The early history of contracture of the palmar fascia. In McFarlane RM, McGrouther DA, Flint MH, eds. Dupuytren's disease. Edinburgh, etc: Churchill Livingstone, 1990:1-9.

Evensen SA, Galdal KS, Nilsen E. LDL-induced cytotoxicity and its inhibition by anti-oxidant treatment in cultured human endothelial cells and fibroblasts. Atherosclerosis 1983; 49:23-30.

Flint MH. The genesis of the palmar lesion. In: McFarlane RM, McGrouther DA, Flint MH, eds. Dupuytren's disease. Edinburgh, etc: Churchill Livingstone, 1990:136-54.

Harvey SC. Hypnotics and sedatives. In: Gilman AG, Goodman LS, Gilman A, eds. Goodman and Gilman's The pharmacological basis of therapeutics. Sixth ed. New York, etc: Macmillan, 1980:355-6.

Havel RJ. Disorders of lipid metabolism. In: Beeson PB, McDermott W, Wyngaarden JB, eds. Cecil textbook of medicine. Fifteenth ed. Philadelphia, etc: WB Saunders, 1979:2002-11. 
Hoover GA, McCormick S, Kalant N. Interaction of native and cellmodified low density lipoprotein with collagen gel. Arteriosclerosis $1988: 8: 525-34$.

Hueston JT. The incidence of Dupuytren's contracture. Med J Aust 1960; $47: 999-1002$.

Hueston JT. The role of the skin in Dupuytren's disease. Ann R Coll Surg Eng 1985; $67: 372-5$.

James JIP. The genetic pattern of Dupuytren's contracture and idiopathic epilepsy. In: Hueston JT, Tubiana R, eds. Dupuytren's disease. Edinburgh, etc: Churchill Livingstone, 1974:37-42.

Kandutsch AA, Heiniger HJ, Chen HW. Effects of 25-hydroxycholesterol and 7-keto cholesterol, inhibitors of sterol synthesis, administered orally to mice. Biochem Biophys Acta 1977; 486:260-72.

Ling RSM. The genetic factor in Dupuytren's disease. J Bone Joint Surg $[B r]$ 1963: 45-B:709-18.

Lund M. Dupuytren's contracture and epilepsy. Acta Psych et Neurol Scand 1941: 16:465-92.
McFarlane RM. Dupuytren's diathesis. In: McFarlane RM, McGrouther DA. Flint MH, eds. Dupuytren's disease. Edinburgh, etc: Churchill Livingstone, 1990:250-2.

Murrell GAC, Francis MJO, Bromley L. Free radicals and Dupuytren's contracture. Br Med J 1987: 295:1373-5.

Noble J, Heathcote JG, Cohen H. Diabetes mellitus in the aetiology of Dupuytren's disease. J Bone Joint Surg [ Br] 1984; 66-B:322-5.

Pojer J, Radivojevic M, Williams TF. Dupuytren's disease: its association with abnormal liver function in alcoholism and epilepsy. Arch Intern Med 1972; 129:561-6.

Rabinowitz JL, Osterman L Jr, Bora FW, Staefien J. Lipid composition and de novo lipid biosynthesis of human palmar fat in Dupuytren's disease. Lipids 1983; 18:371-4.

Skoog T. Dupuytren's contraction with special reference to aetiology and improved surgical treatment: its occurrence in epileptics. Acta Chir Scand 1948; 96 [Suppl 139] 1-190.

Tonkin MA, Burke FD, Varian JPW. Dupuytren's contracture: a comparative study of fasciectomy and dermofasciectomy in one hundred patients. J Hand Surg [Br] 1984; 9-B:156-62. 